any given epidemic there are always certain individuals who never contract the disease. They have a certain natural immunity to that particular disease, and this immunity is due to some physiological peculiarity. So in a field of rusted or mildewed wheat some individual plants show themselves more resistant than their fellows to the species of rust fungus found upon that species of host. By selecting and propagating these immune individuals we may develop an immune race or strain. The problem is not always so simple as here stated. It may happen that a race immune to one disease may be very susceptible to another, or immunity may be accompanied by other qualities altogether undesirable. One might be led to suppose, on reading certain popular articles intended to show how new forms of plants are produced, that it is only necessary to imagine an ideal plant and then set to work to create it. Nothing is farther from the truth than this. Nature does sometimes produce something new, as a stoneless plum, or a nectarine on a peach tree. But man must take the materials furnished by nature, combine them in new ways, or modify them within limits which are usually soon reached. He can not create a wheat plant immune to rust, nor a watermelon resistant to the wilt fungus. But if nature furnishes a few individuals with the desired qualities, man can propagate the individuals possessing those qualities, and by rigid selection maintain the qualities to a high degree. If it is possible to cross the plants with other species or with varieties of the same species, he may be able to combine in the same individual a number of desirable qualities. Having obtained these qualities in one individual, he can best conserve them by vegetative propagation, such as by grafts, cuttings, bulbs or tubers, according to the habit of the plant propagated. He may care nothing whatever about the limits of species or varieties except in so far as their physiological relations help or hinder his combinations. Following MacDougal's method, it may be possible to produce in plants some new characters. But even if it were possible to produce in this way really new species, it is hardly within the range of possibility that we could choose beforehand the kind of a species we would produce. It would be a case of 'cut and try.' If the result be a form with desirable qualities, let it be preserved, but if it be worthless, let it die. Nature has repeated this experiment ten thousand times. If we would imitate her we must search out her secrets in the physiological realm. She conceals them well, but is not unwilling to reveal them to him who questions her with a hearing ear, a seeing eye, and a thinking brain, tools which she herself has given him.

UNIVERSTTY OF MichigaN

James B. Pollock

\section{A PLEA FOR THE STUDY OF THE HISTORY OF MEDICINE AND NATURAL SCIENCES}

For a number of years a new current of thought has been gradually coming to the front in the minds of scientific thinkers of the times. The nineteenth century, the mental development of which is now assured, has of late been severely criticized for its unhistorical character, and perhaps not without reason. Over this inheritance from the preceding generation a certain dissatisfaction is being more and more keenly felt in the most diverse branches of science. The main trend of the last century was naturalistic and economic to a marked degree; so much so, that the new methods discovered in natural science, and

\footnotetext{
${ }^{1}$ Read before the American Anthropological Association, at the meeting of the American Association for the Advancement of Science, December $31,1906$.
} 
the vast progress resulting therefrom, seemed to foreshadow an entirely unprecedented epoch in the history of science, and the generation of that age was only too eager to sever all links connecting it with the accomplishments of former ages.

The inauguration of the twentieth century presents a somewhat contrary aspect. One of its primary tendencies has been towards a restoration of our lost connection with the eighteenth century and with earlier periods, resulting in a movement of such earnest and impressive character that we can not foretell at the present moment whether the eighteenth century will not, at some day not far off, seem nearer to us than the sober prose of the nineteenth.

It is not mere chance that at the dawn of the new age the war-cry 'Historical investigations!' is sounded from all camps, and that in consequence a broader scientific knowledge is obtained through this pursuit of historical research. In nearly all lines, students had become weary of the worn and time-honored ruts, and from the dry atmosphere of specialized specializations yearned for the purer air of loftier heights; and not least among the causes of this reaction was the disappointment due to the misapplications and failures of the evolutionary theory. New ideals were thus created, and found their expression in an extended historical movement, which led to radical changes and to amplifications in literary activity, in academic instruction, and in museum policy-or rather in encouraging prognostics of a new museum era-at least, so far as Germany, Austria and Switzerland are concerned. To give a concise idea of what has been accomplished, and is being proposed to be done in this line, is the object of this paper.

To review even hastily all literary pursuits pertaining to this large field is naturally beyond the scope of my purpose.
The most noteworthy, in my estimation, are the following: the journal Zoologische Annalen, founded in the interests of the history of zoology in 1904 by Max Braun, professor of zoology at the University of Königsberg, and the organization of the Deutsche Gesellschaft für Geschichte der Medizin und der Naturwissenschaften, in Hamburg, on September 25, 1901,-a most active and industrious society, which, now under the able leadership of Professor Karl Sudhoff, of Leipzig, has thus far published six volumes of 'Mitteilungen zur Geschichte der Medizin und Naturwissenschaften.' The pages of this journal are full of interesting original contributions and copious reviews concerning the history of anthropology, botany, zoology, geography, geology, mineralogy, chemistry, physics, mathematics, astronomy, technics, and medicine. A distinguished production of German scholarship is the 'Handbuch der Geschichte der Medizin,' established by Theodor Puschmann, the late celebrated medico-historian of Vienna, and edited by Max Neuburger and Julius Pagel. It was recently completed in three volumes, with thirty-one contributors, and embraces the history of medicine in all its departments and epochs, among all peoples of the globe, inclusive of primitive tribes. Despite its very numerous shortcomings-chiefly due to inaccessibility or want of material, especially on Asiatic medicine, but partially also to lack of historical criticism-it remains, nevertheless, a remarkable monument, but more prospective than retrospective. The recent proposed action of the Berlin Academy of Sciences in regard to the publishing of a complete edition of the Greek medical authors may also be mentioned in this connection; and the new ' epoch-making researches on the life, personality and works of Theophrastus Paracelsus. 
In the academic institutions of Germany and Austria, broad and liberal space is now allotted to instruction and research-work in the history of medicine, natural sciences, and particularly in that of cultural plants and domestic animals. It is an officially acknowledged, fostered and encouraged subject of teaching and study; and there is now hardly any German university, however small, where it would not find a competent representative. Only a year ago (1905) an institute for the study of the history of medicine, in connection with a full professorship, was established at the University of Leipzig, the chair being occupied by Professor Sudhoff, who tells me that thus far there has been an average attendance of from fifteen to twenty-five students in his courses. This institute will regularly issue scientific publications from the beginning of next year (1907).

Berlin has two professors for the history of medicine-Pagel and Schweninger-it having been customary for many years for students of medicine to be allowed to choose their theses from this field, which has been done by many of them with evident success. Regular courses are offered there, besides, in the history of epidemic diseases, of anatomy, of chemistry, of astronomy, of cultural plants. In the last-named subject, four courses are tabulated this winter-one of general character, and three special ones relating to the cultural plants of Africa, and to those of the German colonies and the tropics, respectively. The University of Vienna has likewise two representatives of medical history (Neuburger and $v$. Töply), general courses and a special course on the history of physiology (Kreidl). Innsbruck possesses a specialist in the history of zoology (v. Dalla-Torre). An extraordinariat for the history of medicine has been founded at Würzburg (Helfreich); and courses on the subject are pro- vided for at Bonn, Göttingen, Breslau, Heidelberg, Tübingen, Munich, Marburg, Kiel, Rostock (with even three teachers), further at Graz in Austria; and at Basel, Zürich and Bern in Switzerland:

On November 13, 1906, the cornerstone of the German Museum of Masterpieces of Natural Science and Technics, in Munich, was laid,- the last creation born from this young historical spirit. A question much ventilated now, in the circles of Germany interested, is the plan of a comprehensive museum for the history of medicine, illustrating its development, from the times of prehistoric man down to the present day, in anatomy, surgery, hygiene, endemic diseases and other phases. ${ }^{2}$ Such a medical museum, fully deserving of the name, as yet exists nowhere. The medical faculty of the University of Paris moved a resolution to this effect some years ago, but the scheme has not yet been carried out. The only institution that has thus far made any attempt in this direction is the Germanic Museum of Nürnberg, whose very beautiful collections, however, are restricted rather to pharmaceutical than to purely medical antiquities. The first temporary exhibition relating to medical history was held in Düsseldorf in 1898, on the occasion of the annual assembly of the German naturalists and physicians; and similar tendencies developed at the Russian congress of physicians at Moscow in 1900, with greatest success. $^{3}$

${ }^{2}$ See a paper by Sudhoff, ' Zur Grundsteinlegung des Deutschen Museums von Meisterwerken der Naturwissenschaft und Technik,' Begrüssende Gedanken und Ausblicke (reprint from Münchener Medizinische Wochenschrift, No. 46, 1906).

${ }^{8}$ Compare report on address by B. Reber, ' Über Notwendigkeit und Wert von Sammlungen betreffend die Geschichte der Medizin,' in report on 78. Versammlung Deutscher Naturforscher und Arzte (reprint from Münchener Medizinische Wochenschrift, No. 47, 1906, p. 8). 
I now venture to suggest that such a museum, representing the development of medicine, natural sciences and technics in their whole range, be established in this country, perhaps here in New York, which seems to be the most appropriate place for it; and I am under the strong impression that such an institution would be of wide and universal benefit to our public at large, and would contribute immensely towards the furtherance of science, both natural and historical, and also considerably aid the cause of anthropology. The temporary tuberculosis exhibit in this city last winter may serve as a technical example of what could be accomplished here. If a sufficient number of notable physicians of New York could be interested in the far more extensive plan just proposed-the carrying out of which would not require an exorbitant capital-its realization would seem to be within easy reach. Nothing would be more welcome to us than the sympathetic cooperation of physicians, to interest whom in the study of anthropology we must make many more and larger efforts, especially when we consider how signally anthropology, in its theoretical and practical bearings, has progressed and been advanced by medical men in Europe. One of the foremost tasks of the future American museum devoted to medieal science would certainly be to represent the accomplishments of the hygiene, and technical inventions. In this way we should enlist the interest of physicians in our native population; and students of anthropology might also profit from their mode of viewing the subject or from an active participation in our work. A museum of this type, if developed on the broadest lines, may indeed lead also to new and fruitful anthropological work. I need hardly accentuate here the point that a full historical representation of all endemic and the great epidemic diseases (analogous to the idea of the tuberculosis museums), in connection with the development of hygiene, would be a matter of great public service-an undertaking which should meet with the support of all philanthropists. It goes without saying that a museum of this kind would be a scientific, social and educational potency of the highest order-an agency of social progress, not inferior in rank to art or ethnographical museums.

At the same time I may be allowed to express the wish that the study of the history of medicine and the other natural sciences be taken up in this country with the same energy as on the other side of the Atlantic. I need not dwell here on a discussion of the manifold advantages of such pursuits, as the development of all science as an emanation of human culture naturally falls under the head of anthropology.

The most obvious gain which could be derived from the carrying out of these suggestions would be closer affiliation and more intimate contact of all the sciences. In the pursuit of historical investigations, we are all on common ground, and the character of the subject necessitates mutual dependence and assistance. It logically leads to a plea for cooperation, through the efficiency of which many of our most important problems are awaiting their final solution. Allow me to recall to you the study of the history of cultural plants and domestic animals, as constituting the framework of all higher forms of human culture. These topics have engaged the attention of anthropologists to a very limited extent only, being mainly worked up by botanists and zoologists, and occasionally by geographers and economists. The leading books on the subject are little satisfactory from the historical point of view, while historical investigations already in existence suffer from the lack of botanical or zoological accuracy. There is an unharmonious dissonance be- 
tween these various attempts; and a synthetical representation that should seek to reconcile the conflicting standpoints is still a vain hope. The reason is the isolation of the single sciences, each of which, being restricted to its peculiar resources and methods, is intent on solving a problem in which a goodly number of them are involved. Naturally, only one solution to a problem is possible, whether it be attacked through physical or historical research; and if the results obtained by either are mutually contradictory, this is equivalent to saying that the particular science alone is unable to solve it, and that the solution should be undertaken by a concentration of energy of all the sciences concerned in the specific case. To cite a practical example, take the origin and propagation of our cereals, or the long history of the domestication of the ox or the horse-problems around which, finally, the most ancient history of Asia and Europe centers. There is no science which, by the mere exercise of its own limited faculties, could reach a decisive solution of them; but I am fully confident of ultimate success through a cooperative combination of the various sciences involved, which, in this case, are geology, botany, zoology, archeology, history and anthropology. The individual can not master all these sciences; and, instead of dividing our strength by working singly from isolated positions, we should advocate the uniting of all available forces for the best good of the same cause. The identical observation holds for all historical studies of sciences. The students of Oriental fields, for example, whether their work be in the Egyptian, Arabic, Indian or Chinese departments, are almost daily confronted with the wonderfully rich scientific lore of these peoples referring to subjects in which they themselves are not competent; but it is on the shoulders of these very students that the accumulation of a large portion of the material rests, on which the historian of science can build. One of the most remarkable instances of this sort of cooperation which I have in mind, and which might be extended over many other lines, was the association of the Orientalist Karabacek in Vienna with the naturalist Johann Wiesner, for the investigation of ancient Arabic, Chinese and Turkestan ragpapers, the microscopical and chemical analysis of which confirmed step by step, in minutest details, every result of the history of the invention of rag-paper contributed from Chinese and Arabic sources. The result of their joint labors, carried through many years, I consider one of the greatest triumphs of modern science. But there are many more culture problems of equal importance whose solution must be achieved in a similar manner. Let me refer you only to the history of the invention of gunpowder and of the magnetic compass, both of which are still very obscure in fundamental points, and the working-up of which requires a whole force of well-trained specialists-Arabists, Sanskritists, Sinologues, and men well versed in chemistry, technology, physics and their history.

A study of some of the principal questions in this field is further of profound significance in an interpretation of the methods and results of anthropology. Allow me to exemplify this briefly from the instance of mathematical history. The relation of the concepts of mathematics to the human mind and to the development of culture is still a matter of controversy, and one of burning actuality, just at the present time. A solution on the basis of an historical method is one of the aspects of this problem. The historical position of mathematics; however, is as yet very far from being defined, and no criterions are 
agreed upon which will admit at the outset of stamping a mathematical thought and theorem as borrowed or independent. The most striking feature in the history of this science is the fact that the same results, even in the highest branches of it, have frequently been obtained by different peoples and at various epochs, with little or no possibility of pointing out an historical connection between such coincidences. The quadrature of the circle, for example, was made the object of correct speculation in China, even in pre-Christian times; or the rule of Horner 'for solving equations of all orders,' established in 1819, was known to the Chinese 520 years earlier, when, in an arithmetical treatise published in 1299, roots were extracted as high as the thirteenth power. ${ }^{*}$ Paul Harzer, ${ }^{,}$astronomer at the University of Kiel, last year submitted the mathematical knowledge of ancient Japan to a careful and ingenious examination, and has arrived at the conclusion that the Japanese found spontaneously adequate evaluations of the ratio $\pi$, and made the independent discovery of the binomial theorem, which they utilized for obtaining important results. Modern criticism, with its aggressiveness towards the groundwork of human knowledge, towards even that which seems most secure, has recently attacked also the foundations of mathematics, generally looked upon as the most unobjectionable science, and has designated its results, like those of other sciences, as more or less conventional, not necessitated by the nature of the human mind. ${ }^{\circ}$ To us, mathematics is essentially an outcome of human culture; and the question arising from an anthropological view-point

*A. Wylie, 'Jottings on the Science of the Chinese Arithmetic,' in his ' Chinese Researches' (Shanghai, 1897), pp. 163, 184, 185.

'Paul Harzer, 'Die exakten Wissenschaften im alten Japan' Kiel, 1905.

- Harzer, ibid., p. 26. is, Are the phenomena of mathematical thoughts to be considered as on an equal footing with those of language, religion or medicine, and, accordingly, capable of methodical anthropological treatment, or are they the particular productions of individual thinkers, and, accordingly, conducive only to an exclusively historical analysis? It is impossible for the present to pronounce a verdict on this intricate problem, though I should like to say tentatively, and with all reserve, that the present state of our knowledge of the mathematics of India, China and Japan would almost seem rather to favor the acceptance of the former theory. At all events, the ventilation of this question is well illustrative of the paramount importance of the study of the history of mathematics and its principal bearings on our views of the intellectual history of man.

The practical proposition which I finally wish to lay before you is, that working committees, cooperative in character, be organized, each consisting of a limited number of members selected equally from students of natural sciences and students of anthropology, especially those in Oriental fields, and pursuing given problems viribus unitis. Each of these unions, which need not be of an official character, but may be freely private voluntary alliances of interested students, should be in charge of a particular branch of science. Altogether, seven may be necessary-one for the study of the history of mathematics and astronomy; others for that of cultural plants, domestic animals, physics, chemistry, technology and medicine. Each committee should be so constituted that the united forces of its laborers will represent a consummate systematic knowledge of the subject in question, and take up, suggest, encourage and elaborate pending problems by the concerted action of all its partici- 
pants. By this method of research, much time and labor would be saved, and more positive and enduring results would be secured.

In concluding, let me call your attention also to the fact that we do not yet possess a history of anthropology, and that broadminded contributions to the history of our science are an urgent necessity. Goethe has said somewhere that the history of science is the science itself; and I believe, further, that only by a correct appreciation of the development of our science are we able to be just towards our fellowworkers and ourselves. Now that so many of our prominent leaders, like Brinton, Powell, Cushing, Virchow, Bastian and Ratzel, have passed away, whatever we may personally think of the value of their work and its influence upon future generations, it is our duty to come to an objective understanding of their activity and aspirations, and to write the pragmatic history of anthropology in the life and labors of its most conspicuous representatives.

\section{Berthold Laufer}

\section{SCIENTIFIC BOOKS}

THE MISSION FOUREAU

Documents Scientifiques de la Mission Saharienne, d'Alger au Congo par le Tchad. Par F. Foureau, chef de la mission. IIme fasc., Orographie, Hydrographie, Topographie, Botanique; IIIme fasc., Geologie, Petrographie, Paléontologie, Esquisse Ethnographique, notes sur la faune, Prehistorique, Aperçu Commercial, Conclusions économiques, Glossaire. Index. Atlas. Paris, Masson et Cie. 1905. 4to, 1210 pp., maps and ills.

While the Mediterranean and mid-African colonies of France have been for some time fairly well known, the efforts to connect them by a line of geographical exploration had been rendered ineffectual by the difficulties and dangers of the route through the desert, and the hostility of the natives. Several expedi- tions met with disaster and were exterminated by the fanatical population.

Finally the expedition organized and carried out by Foureau in 1898 to 1900 met with success. This happy result had been well earned, because Foureau had already given twentythree years to Saharan exploration under the auspices of the Ministry of Public Instruction. In 1898 his itineraries already amounted to 21,000 kilometers, of which more than 9,000 $\mathrm{km}$. were in previously unexplored country.

In 1894, M. Renoust des Orgeries left to the Société de Géographie a considerable sum of money, to be devoted to the geographical development of the French colonies. Out of this legacy the society devoted 250,000 francs to the purpose of the Sahara Mission, a sum to which the government added not only funds but an escort of 250 picked soldiers under the command of a most competent African officer, Com. Lamy, who fell during an attack by an African chief, in the very moment when the success of the expedition was assured.

With the concurrence of men of science, the commander of the expedition has prepared this report, which by the assistance of government and various scientific societies, is now published in magnificent style by the Société de Géographie, with a preface by Alfred Grandidier.

Together with the reports indicated by our synopsis of the title, the work is replete with well-executed maps, sketches, plans of towns, views and everything which could be of use to future explorers, including minute notes as to the presence, amount and quality of water, pasturage, cultivated land, wild animals, etc. If one is startled by the frequent notation, along the river, of the presence of 'oyster banks,' hundreds of miles from the sea, reflection recalls the colonies of the fresh-water Atheria to which these notes undoubtedly refer.

The mass of information in this encyclopedic work, it is, of course, impossible to summarize. A few notes may, however, have interest for the reader. While a large portion of the herbarium suffered from termites and the wreck of a canoe, nevertheless a good number of plants are recorded; and numerous 